NBER WORKING PAPER SERIES

\title{
ARE APPARENT PRODUCTIVE SPILLOVERS A FIGMENT OF SPECIFICATION ERROR?
}

Susanto Basu

John G. Fernald

Working Paper No. 5073

\section{NATIONAL BUREAU OF ECONOMIC RESEARCH 1050 Massachusetts Avenue \\ Cambridge, MA 02138 \\ March 1995}

We thank Robert Barro, Eric Bartelsman, Ricardo Caballero, Barbara Fraumeni, Dale Jorgenson, Greg Mankiw, Joe Mattey, Phil Panet, and an anonymous referee for helpful comments and discussions, and participants in the Harvard Macro Lunch for their comments. Basu is grateful to the National Science Foundation for financial support. This paper is part of NBER's research program in Economic Fluctuations. Any opinions expressed are those of the authors and not those of the Board of Governors of the Federal Reserve System, other members of its staff, or the National Bureau of Economic Research.

(C) 1995 by Susanto Basu and John G. Fernald. All rights reserved. Short sections of text, not to exceed two paragraphs, may be quoted without explicit permission provided that full credit, including (C) notice, is given to the source. 


\title{
ARE APPARENT PRODUCTIVE SPILLOVERS A FIGMENT OF SPECIFICATION ERROR?
}

\begin{abstract}
Using data on gross output for two-digit manufacturing industries, we find that an increase in the output of one manufacturing sector has little or no significant effect on the productivity of other sectors. Using value-added data, however, we confirm the results of previous studies which find that output spillovers instead appear large. We provide an explanation for these differences, showing why, with imperfect competition, the use of value-added data leads to a spurious finding of large apparent external effects.
\end{abstract}

Susanto Basu

Department of Economics

University of Michigan

Ann Arbor, MI 48109-1220

and NBER
John G. Fernald

Stop 20

Federal Reserve Board

Washington, DC 20551 
Does an increase in the output of one manufacturing sector significantly increase the productivity of other sectors? Caballero and Lyons $(1990,1992)$ develop a simple and ingenious statistical framework for detecting such externalities. Using industry data on value added as their measure of output, they establish the stylized fact that there is a strong positive correlation between sectoral productivity and aggregate activity. They interpret their finding as evidence of productive externalities. In this paper, we provide an alternative explanation for this stylized fact: with imperfect competition, value-added data predictably lead one to find large apparent externalities even if such externalities do not exist.

The Caballero-Lyons findings are commonly interpreted as evidence for true productive spillovers at the plant level. An increase in the activity of the automobile industry somehow increases the productivity (that is, shifts the production function) of, say, a chemical factory. This interpretation poses a challenge to economic theorists to articulate a well-specified model showing the mechanism through which this spillover operates. The idea of "thick markets externalities" is sometimes proposed, in which search costs are lower when activity is higher. It is difficult, however, to identify many examples of such thick-markets effects that affect specific manufacturing plants. Hence, the magnitudes involved seem too small to explain large spillovers. If the Caballero and Lyons findings reflect true productive spillovers, then we still await a compelling theoretical explanation of the mechanism.

Another feature of the value-added estimates is their uniform implication of strongly diminishing returns to scale at the level of the individual producer. This finding has not received as much attention as the finding of large external effects. This is a mistake. We argue that there are a number of reasons for rejecting the very low returns to scale estimated from value-added data. Most importantly, as we show, returns to scale as low as those estimated from value added imply that firms consistently sell output below marginal cost. This is not a sensible result, and it naturally casts doubt on the other result of value-added estimates, the finding of large external effects.

By contrast, our alternative interpretation of the Caballero-Lyons stylized fact suggests that there 
is no need for a theoretical model of spillovers and that firms do not in fact sell output below cost. We apply the same estimation methods to data on gross output in two-digit manufacturing industries, and find little evidence of productive spillovers to output but strong evidence that internal returns to scale are approximately constant. We then construct a measure of value-added output from our data, and like Caballero and Lyons, find large apparent spillovers and diminishing returns. We provide an explanation for these differences, showing why regressions with value-added data are misspecified and what form this misspecification should take. After correcting for these misspecifications, we again find, even with value-added data, that external effects are small or nonexistent and returns to scale are about constant.

A straightforward argument shows why value-added data may give unreliable results. Note first that gross output is the natural measure of output for a firm or industry, not value added: gross output is books, value-added is books without paper or ink. Value added is thus an economic index number without physical interpretation. As an index number, value added is not atheoretic: its construction implicitly assumes competition and constant returns to scale.

Intuitively, real value added is like a partial Solow residual, constructed by taking gross output and subtracting the productive contribution of intermediate inputs. To do this, one must know or infer the marginal product of these intermediate inputs. Real value added is constructed assuming that this marginal product is observable from factor payments to intermediate goods. With imperfect competition, however, the marginal product exceeds the factor payments. Thus, value added does not properly account for the productive contribution of intermediate inputs: value added, in general, depends on intermediate input use. Proxies for output externalities, such as aggregate inputs or aggregate output, are also reasonable proxies for the effect of the omitted intermediate inputs. Hence, with increasing returns and/or imperfect competition, value-added data can lead to a spurious finding of large apparent externalities. Given the positive correlation of aggregate and individual inputs, an incorrect finding of large externalities also biases down the estimate of internal returns to scale. 
Our finding that there are no output spillovers suggests a sharp dichotomy between the mechanisms that might be responsible for long-run technological progress and those that are plausible sources of procyclical productivity or business cycle fluctuations. Over the long run, it is quite reasonable to think that $R \& D$ spillovers across industries, the transmission of technologies via trade, and the development of new types of intermediate inputs play a crucial role in growth. There are a number of detailed, plausible models of these types of spillovers and their roles in long-run growth. ${ }^{1}$ The assumption of R\&D spillovers receives empirical support from the results of Jaffe (1986) and Griliches and Lichtenberg (1984). Indeed, one of the most interesting results of Bartelsman, Caballero, and Lyons (1994) is their finding that long-run productivity growth in an industry is associated with increased activity in its upstream, input-producing, industries.

On the other hand, the literature explaining business cycles as a consequence of technological externalities has made relatively little progress since the seminal contribution of Diamond (1982). Hence the results of Caballero and Lyons have drawn a great deal of interest, because they seem to imply that large, high-frequency technological externalities exist regardless of their precise source. ${ }^{2}$ However these results have also been the focus of much skepticism, since, as we noted before, it is difficult to see how spillovers of the size their estimates imply might work at business cycle frequencies. Our results indicate that the skepticism is justified: output spillovers do not appear important at these frequencies. Thus, our results suggest that business cycle models based on "strategic complementarities" or multiple equilibria are, like the aggregate demand-driven models of Weitzman (1982) and Kiyotaki (1988), more plausibly based on pecuniary externalities than on short-run technological spillovers.

The paper is structured in five sections. In the first section we describe our method for detecting

\footnotetext{
${ }^{1}$ See, for example, Romer (1987), Grossman and Helpman (1990), Ciccone and Matsuyama (1993).

${ }^{2}$ Based on the Caballero-Lyons findings, a number of papers have incorporated output externalities of this type into theoretical or empirical work. See, for example, Baxter and King (1991), and Braun and Evans (1991).
} 
externalities. In Section II, we examine the biases that result from using value-added data. In Section III, we discuss the data we use. We present and discuss our empirical results in Section IV. We then conclude with a brief summary.

\section{Method for Finding Externalities}

The theory behind our investigation follows closely the setup of Caballero and Lyons (1989, 1990, 1992). The discussion here parallels that found in their papers. We begin with the following production function for an industry:

$$
Y_{i}=F\left(K_{i}, L_{i}, M_{i}, Z_{i}, T_{i}\right)
$$

$\mathrm{Y}$ is gross output (not value added). $\mathrm{K}$ and $\mathrm{L}$ are primary inputs of capital and labor, while $\mathrm{M}$ is intermediate inputs of energy and materials. $\mathrm{Z}$ is an externality index, and $\mathrm{T}$ is an index of the state of technology. We assume that the production function is homogeneous of degree $\gamma$ in capital, labor, and intermediate goods. $\gamma$ is thus the degree of internal returns to scale.

We allow firms to have some degree of monopoly power in the goods markets, though we assume that they are price takers in factor markets. We also assume that all factors are freely variable. Under these assumptions, the first-order conditions for cost minimization imply that the elasticity of output with respect to any factor $\mathbf{J}$ equals a markup $\mu$ multiplied by the share of that input in total revenue, $s_{\mathrm{J}}$ :

$$
\left[\frac{F_{J} J}{Y}\right]=\mu\left[\frac{P_{J} J}{P Y}\right] \equiv \mu s_{J}, \quad J=K, L, M .
$$

$P$ is the price of gross output, $F_{J}$ is the marginal product of input $J$, and $P_{J}$ is the price of the $J$ th input 
as perceived by the firm. Note that the price of capital, $\mathrm{P}_{\mathrm{K}}$, must be defined as the rental cost of capital. ${ }^{3}$ It does not include possible profits, which generally are also payments to capital. With perfect competition, where $\mu=1$, equation (2) states that the elasticity of output with respect to any input equals the input's share in revenue. Under imperfect competition, the elasticity of output exceeds the revenue share.

By definition, the sum of the output elasticities equals the degree of returns to scale $\gamma$. Combining this definition with the first-order conditions (2) implies that

$$
\gamma=\mu\left[\frac{P_{K} K+P_{L} L+P_{M} M}{P Y}\right] .
$$

Rearranging equation (3), we find

$$
\frac{\mu}{\gamma}=\frac{\text { Revenue }}{\text { Costs }}=1+\frac{\text { Profits }}{\text { Costs }}
$$

Thus, if the markup exceeds the degree of returns to scale, the firm or industry makes positive profits. If the markup equals the degree of returns to scale, the firm makes zero profits.

Note that unless the profit rate is constant, then it cannot be the case that both $\mu$ and $\gamma$ are constant structural parameters. We assume that returns to scale $\gamma$ is the structural parameter, and implicitly allow the markup to vary over time and over industries, as required by equation (4). Define $c_{\mathrm{fi}}$ to be the share of input $J$ in the total cost of industry i. From equations (2) and (3), the output

\footnotetext{
${ }^{3}$ We assume that capital is always rented in the quantity desired. If, however, capital is quasi-fixed (sunk in the short run), then the marginal product of capital does not equal its steady-state rental rate but rather its current shadow rental. That is, the Hall-Jorgenson user cost of capital (equation (14) below) should be multiplied not by the price of investment goods, but by the shadow value of capital, marginal q. (The shadow rental also includes expected capital gains.) This problem is not significant, for two reasons. First, quasi-fixity affects only the period-by-period shares, not the growth rate of capital or any other input. These shares are constant to a first-order Taylor approximation, so any errors caused by mismeasurement are formally second order. Second, even if mismeasurement is large, the strongest effect is on capital's share. But the growth rate of capital has little correlation with the business cycle, so errors in measuring capital's share are again relatively unimportant. Simulations by Caballero and Lyons (1989) indicate that quasi-fixity leads to at most a 3 percent bias in the estimated coefficients.
} 
elasticity with respect to input $\mathrm{J}$ is $\mu \mathrm{s}_{\mathrm{Ji}}=\gamma c_{\mathrm{ji}}$. Taking the logarithmic total differential of $\mathrm{Y}$ and substituting for the output elasticities, we find:

$$
\begin{aligned}
d y_{i} & =\gamma \cdot\left[c_{K i} d k_{i}+c_{L i} d l_{i}+c_{M i} d m_{i}\right]+d z_{i}+d t_{i} \\
& \equiv \gamma \cdot d x_{i}+d z_{i}+d t_{i} .
\end{aligned}
$$

Lower-case letters represent logs of their upper-case counterparts, so all of the quantity variables in (5) are log differences, or growth rates. For convenience, we normalize the elasticities of output with respect to external effects $\mathrm{Z}$ and technology $\mathrm{T}$ to equal $1 . \quad \mathrm{dx}_{\mathrm{i}}$ is a cost-weighted sum of the growth rates of the various inputs. Intuitively, equation (5) says that the growth rate of output equals the growth of inputs multiplied by the degree of returns to scale, plus the contribution of productivity shocks. If there are constant returns and perfect competition--so the cost shares are the revenue shares--then equation (5) is just the standard equation defining the industry-level Solow residual.

If we use equation (5) to estimate returns to scale, it is necessary to model the externality term $\mathrm{dz}_{\mathrm{i}}$. Caballero and Lyons model $\mathrm{dz}_{\mathrm{i}}$ by arguing that there are positive spillovers at any level of production that become internal at a higher level of aggregation. For example, if a firm's productivity is enhanced by the output of other firms within the industry, this effect is internal to the industry. But the productivity of a firm may also be enhanced by increases in output of other industries. These effects are external at the industry level.

Following their method, we investigate the importance of externalities across two-digit manufacturing industries. We then look for external effects in these industries from the one-digit level, aggregate manufacturing. Caballero and Lyons (1989) and Bartelsman, Caballero, and Lyons (1994) advocate estimating the following regression:

$$
d y_{i}=\gamma \cdot d x_{i}+\kappa \cdot d x+d u_{i}
$$

$\mathrm{dx}$ is the aggregate input growth rate, where the growth rates of the inputs are appropriately weighted by their cost shares. That is, $\mathrm{dx}$ is the analogue, at the aggregate manufacturing level, of the sectoral 
input growth rates $\mathrm{dx}_{\mathrm{i}}$. This serves as a natural proxy for aggregate manufacturing output, dy. It mitigates the potential endogeneity problem, however, that arises from the direct influence of sectoral technology shocks on aggregate output.

Of course, there is still an endogeneity problem, coming from the probable correlation between sectoral technology shocks and sectoral input use: input use probably rises to take advantage of the higher level of productivity. So if one has suitable instruments, the correct procedure is to project the righthand-side variables on instruments that are arguably exogenous with respect to shocks to technology.

\section{The Biases from Using Value Added Data}

The proper measure of output for estimating equations such as (6) is gross output. From the perspective of a firm or an industry, all inputs are symmetric: the firm faces the possibility of substituting among all factors of production--capital, labor, and intermediate inputs of energy and materials--to produce this gross output. Researchers such as Hall and Caballero and Lyons instead use data on value added in order to estimate markups, returns to scale, and external effects. Measures of real value added attempt in some way to subtract from gross output the productive contribution of intermediate goods. This generates a measure of "net output" which, it is hoped, depends only on primary inputs of capital and labor.

Unfortunately, attempts to estimate structural parameters from data on value added are in general misspecified. In this section, we explore the statistical properties of real value added when perfect competition and constant returns to scale do not hold. We show that in the presence of markups, intermediate inputs directly affect value added. Proxies for externalities, such as aggregate inputs, are correlated with this omitted sectoral intermediate inputs. The misspecifications caused by using valueadded data may thus show up as external effects. With value-added data, one therefore cannot distinguish an apparent finding of externalities from a rejection of constant returns and competition. 
Our argument differs from that emphasized in the production function literature. It is well known from that literature that a value-added production function independent of intermediate inputs exists if and only if capital, labor, and technology are separable from intermediate inputs in the gross output production function (see, for example, Bruno (1978)). Our observations hold even if the production function is separable.

The preferred way to measure output net of materials use is to create a Divisia index. ${ }^{4}$ The National Income and Product Accounts instead rely primarily on the method of double-deflation, although other methods are used for some industries. In Appendix I, we discuss the relationship between the Divisia-index measure and two measures used by NIPA: single- and double-deflation. We show that these measures are subject to the same biases as the Divisia measure, plus an additional bias in each case. In what follows, we omit industry subscripts for simplicity. Let $s_{M}$ be the share of materials in revenue. The growth rate of the Divisia index of industry real value added $d v$ is defined implicitly by

$$
d y \equiv\left(1-s_{M}\right) d v+s_{M} d m
$$

That is, aggregate output is a Divisia index of value added and intermediate inputs, weighted by shares in revenue. This equation can be rearranged to give:

$$
d v=\frac{\left[d y-s_{M} d m\right]}{\left(1-s_{M}\right)}
$$

The economic justification for this definition is easily seen if there is perfect competition and constant returns. The numerator subtracts the productive contribution of intermediate-input growth from output growth. The growth rate of value added must then be normalized so that if gross output and intermediate inputs grow at the same rate, then value added also grows at that rate. This is accomplished by dividing through by the share of nominal value added in the value of gross output, $1-s_{M}$.

\footnotetext{
4 See Sato (1977) or Arrow (1974).
} 
These two adjustments are only correct, however, under constant returns to scale and competition. Value added is like a partial Solow residual, and Solow residuals do not correctly measure the productive contribution of inputs if constant returns and/or competition fails. In particular, with imperfect competition the output elasticity with respect to intermediate inputs exceeds their share in revenue.

We can express analytically the misspecification that arises from failures of constant returns and competition. Substituting for the differential of output from equation (5) in equation (8), we can write value-added growth as:

$$
d v=\gamma\left(\frac{c_{K} d k+c_{M} d m}{1-s_{M}}\right)+\left(\frac{\gamma \cdot c_{M}-s_{M}}{1-s_{M}}\right) d m+\frac{d z+d t}{1-s_{M}}
$$

or,

$$
d v=\gamma \cdot\left[\frac{1-c_{M}}{1-s_{M}}\right] d x^{v}+\left(\frac{\gamma \cdot c_{M}-s_{M}}{1-s_{M}}\right) d m+\frac{d z+d t}{1-s_{M}}
$$

where $\mathrm{dx}^{\mathrm{v}}$ is the value-added analogue of $\mathrm{dx}$ :

$$
d x^{\nu}=\left(\frac{c_{K}}{c_{K}+c_{L}}\right) d k+\left(\frac{c_{L}}{c_{K}+c_{L}}\right) d l .
$$

Using equation (3), we can rewrite this as

$$
d v=\gamma \cdot\left[\frac{1-c_{M}}{1-s_{M}}\right] d x^{v}+(\mu-1)\left(\frac{s_{M}}{1-s_{M}}\right) d m+\frac{d z+d t}{1-s_{M}}
$$

Equation (12) provides the basis for our discussion of what it is that value added measures. As expected, the growth rate of the index of value added depends on returns to scale, primary input growth, technological progress, and externalities. Surprisingly, however, value-added growth also depends on markups and intermediate input growth.

If there is competition and constant returns, then the growth rate of value added equals the growth 
rate of primary inputs plus technological progress. That is,

$$
d v=d x^{v}+\frac{d z+d t}{1-s_{M}} .
$$

One implication of equation (13) is that if $s_{M}$ is approximately constant, then as Hall (1990) claims, under competition and constant returns the productivity residual calculated from value added is uncorrelated with any variable that neither causes productivity shifts, nor is caused by productivity shifts. In addition, $\mathrm{dx}^{v}$ can be calculated with either cost or revenue shares, since there are no profits.

With imperfect competition and non-constant returns, however, there are two sources of misspecification apparent in equation (12). The first misspecification is that in the presence of markups, the growth of materials and energy directly changes the growth rate of value added. Intuitively, value added is calculated by subtracting from gross output the contribution to production of intermediate goods, assuming that the elasticity of output with respect to materials equals its revenue share. With markups, the elasticity of output with respect to materials exceeds its revenue share. Hence, some of the productive contribution of energy and materials inputs is incorrectly attributed to value added. For example, with imperfect competition an energy-price shock that causes energy use to fall lowers the growth rate of value added.

This omitted growth in materials will appear as an external effect, since aggregate inputs of capital and labor serve as a proxy for intermediate input use in each sector. This seems plausible a priori, since part of the output of each sector is used as intermediate inputs in other sectors. The data support this conclusion as well. Using our data set, we find that aggregate inputs serve as a good proxy for sectoral intermediate input use, even after controlling for own-inputs. ${ }^{5}$ Hence, by including aggregate inputs (or aggregate output), Caballero and Lyons include a proxy for sectoral intermediate input use in their regressions.

\footnotetext{
${ }^{5}$ We regress $\mathrm{dm}_{\mathrm{i}}$ on $\mathrm{dx}_{\mathrm{i}}^{v}$ and $\mathrm{dx} \mathrm{x}^{\mathrm{v}}$. The coefficient on $\mathrm{dx}^{\mathrm{v}}$ is 0.52 , with a t-statistic of 12 .
} 
The second misspecification is that the coefficient multiplying primary input growth $\mathrm{dx}^{\mathrm{v}}$ in equation (12) is not, in general, the true degree of returns to scale. The reason for this is that the output elasticity with respect to primary factors equals the degree of returns to scale multiplied by the cost share going to primary factors, or $\gamma \cdot\left(1-c_{M}\right)$, whereas the calculation of value added "grosses up" this elasticity by $\left(1-s_{M}\right)$. This is the correct adjustment if there are no economic profits, so that the cost shares equal the revenue shares. In this case, the coefficient on primary input growth is the true degree of returns to scale. If there are economic profits, however, this divisor is too large. Hence, once we control for the omitted-variable bias from intermediate inputs, the coefficient on primary inputs provides a downwardbiased estimate of the true degree of returns to scale.

It is unclear a priori what effect this second misspecification should have on estimated externalities. If $\left(1-c_{M}\right) /\left(1-s_{M}\right)$ is constant over time, then the coefficient on primary inputs is a constant structural parameter; after controlling for the omitted variable bias, this second misspecification has no effect on the estimate of external effects. If $\left(1-c_{M}\right) /\left(1-s_{M}\right)$ is strongly procyclical, on the other hand, this will bias the estimated externality term upwards. In our data, there appears to be little cyclical pattern to $\left(1-c_{M}\right) /\left(1-s_{M}\right)$. Hence, we expect this second misspecification to have relatively little effect on the estimated externality.

In principle, we can estimate equation (12) directly, obtaining estimates of internal returns to scale $\gamma$, the markup of price over marginal cost $\mu$, and the size of any external effects. By estimating this equation, we can confirm the empirical importance of the two misspecifications we identify above. It is inconsistent, however, to estimate this equation by constraining both the markup and the degree of returns to scale to be constant over time, as we discussed in Section I. Hence, we instead estimate equation (10), which eliminates this inconsistency by implicitly allowing the markup to vary over time and over industries.

Equation (10) shows how to augment data on vaiue added and primary inputs in order to correct 
for the effects of markups and increasing returns. In Section IV, we estimate this equation both with our value-added data, and with the NIPA data used by Caballero and Lyons, augmented with our data on materials use and the materials share in revenue and cost. This is of interest because the two sources of data have different methodological underpinnings. Hence, by estimating equation (10), we confirm the extent to which the misspecifications we identify explain results with their data, as well as with our own. As discussed in section $\mathrm{I}$, we model $\mathrm{dz}$ as $\kappa \mathrm{dx}$.

Note that Caballero and Lyons (1992) attempt to control for the flaws of value-added data without directly using data on materials use or the materials share. In their regressions they include as a righthand-side variable either the quantity of energy used in the industry, or the price of oil relative to the price of industry output. We interpret the inclusion of the quantity of energy as a proxy for the omitted variable of sectoral intermediate input growth, and the inclusion of the relative price of oil as an attempt to control for the bias resulting from double-deflation (see Appendix 1). Of course, one wants to control for both failures of the NIPA data. To that extent, one would want to include both variables simultaneously rather than sequentially.

These are, however, quite imperfect ways to correct for the failures of value-added data. Energy use is only about five percent of a typical sector's use of intermediate goods, so including it does not correctly control for the omitted variable, which is total use of intermediate goods. Similarly, including the relative price of oil may partially proxy for the part of the double-deflation bias that depends on changes in relative prices. But again, the relevant price is the price of materials as a whole, not of oil alone. In any case, including the relative price of oil does not solve any of the problems we identify in equation (12).

We do not face the same problems as Caballero and Lyons in our estimation, because we do not use value-added data. As we discuss in the next section, we instead use data on gross output by 2-digit manufacturing industry. The discussion in this section provides an explanation for differences in results 
using gross-output data and using value-added data. In particular, it is apparent that the use of valueadded data may lead to a spurious finding of external effects.

\section{The Data}

We use unpublished data provided by Dale Jorgenson and Barbara Fraumeni on inputs and outputs for 21 manufacturing industries of the U.S. economy, for the years 1953-1985. These data are at roughly the two-digit SIC level. ${ }^{6}$ They are part of Jorgenson's long-term research effort, with a number of coauthors, aimed at creating a complete set of national accounts for both inputs and outputs at the level of individual industrial sectors as well as the economy as a whole. The purpose of these accounts is to allow Jorgenson to allocate U.S. economic growth to its sources at the level of individual industries. Hence, these data seek to provide measures of output and inputs that are, to the extent possible, consistent with the economic theory of production. ${ }^{7}$

Inputs are separated into capital, labor, and intermediate inputs of energy and materials. Conceptually, Jorgenson divides labor input into hours worked, and average labor "quality." This quality adjustment takes account of differences in the sex, age, and educational composition of the labor force, assuming that observed wage differences reflect differences in relative marginal products. Similarly, Jorgenson constructs a quality- or composition-adjusted measure of capital input analogously to labor input, seeking to weight the input of different types of capital by their relative rental rates. We obtained the data on labor and capital input both with and without the quality adjustment. This allows us to confirm that none of our substantive results are affected by these adjustments.

For our purposes, however, there are two crucial aspects of Jorgenson's data. First, sectoral

6 There are only 20 two-digit industries. In Jorgenson's data, the transport-equipment industry is divided into two sectors, "motor vehicles" (SIC 371) and "other transport equipment" (SIC 372-379).

7 For a complete description see Jorgenson, Gollop, and Fraumeni (1987) or Jorgenson (1990). 
output is measured as gross output, not value added. Second, the data include sectoral intermediate inputs in each year, compiled from the Bureau of Economic Analysis input-output tables. The input-output tables allow Jorgenson to compile complete intermediate inputs-- including energy, materials, and business services. These two aspects allow us to treat intermediate inputs symmetrically with primary inputs in modeling production. They also allow us to augment the data used by Caballero and Lyons, in order to correct the biases that arise from their use of value-added data.

The Caballero-Lyons data include measures of sectoral value added, from the National Income and Product Accounts. This is a double-deflated measure of value added, rather than the theoreticallypreferable Divisia index. They also include data on sectoral labor hours, from NIPA, and data on sectoral net capital stocks, from the BEA. Neither measure of labor or capital input includes any adjustment for changes in composition, or quality, over time. (They are thus similar to Jorgenson's data without the quality adjustment, except that the capital stock incorporates different depreciation assumptions, and does not include land or inventories.)

As Hall $(1986,1988)$ notes, with imperfect competition we cannot assume that required payments to capital are simply a residual after all other factors are paid. To estimate the required payments to capital, we follow Hall and Jorgenson (1967), Hall (1986, 1990), and Caballero and Lyons, and compute a series for the user cost of capital $r$. The required payment for any type of capital, $P_{K} K$, is then $r \pi^{\mathrm{K}} \mathrm{K}$, where $\pi^{\mathrm{K}} \mathrm{K}$ is the current-dollar value of the stock of this type of capital. In each sector, we use data on the current value of the 50 types of capital, plus land and inventories, distinguished by the BEA in constructing the national product accounts. Hence, for each of these 52 assets, we compute the user cost of capital as 


$$
r_{s}=\left(\rho+\delta_{s}\right) \frac{\left(1-I T C_{s}-\tau \cdot d_{s}\right)}{(1-\tau)}, s=1 \text { to } 52 .
$$

$\rho$ is the required rate of return on capital. For each asset, $\delta_{s}$ is the depreciation rate, ${ }^{8}$ ITC $_{s}$ is the investment tax credit, and $d_{s}$ is the present value of depreciation allowances. $\tau$ is the corporate tax rate. We assume that the required return $\rho$ equals the dividend yield on the S\&P 500. We obtained unpublished data on $\mathrm{ITC}_{\mathrm{s}}, \mathrm{d}_{\mathrm{s}}$, and $\tau$ from Dale Jorgenson. ${ }^{9}$

The derivations in Sections I and II are presented in continuous time. We approximate them in discrete time by replacing logarithmic derivatives with log differences, and using average shares in adjacent time periods in place of instantaneous shares. For example, in order to compare the results we find with Jorgenson's data more directly with the results from Caballero and Lyons' data, we calculate a series for real value added from Jorgenson's data. Letting $\overline{\mathrm{s}}_{\mathrm{M}}$ be the average value in periods $\mathrm{t}$ and $\mathrm{t}-1$ of the share of intermediate inputs in revenue, we approximate equation (8) in discrete time as

$$
\Delta L n V_{i t}=\left[\frac{1}{1-\bar{s}_{M}}\right]\left[\Delta \operatorname{Ln} Y_{i t}-\bar{s}_{M} \Delta \operatorname{Ln} M_{i t}\right] .
$$

This is the Tornquist approximation to the continuous-time Divisia index in equation (8).

As discussed in Section I, there is a clear argument for using instrumental variables in estimating equation (5). Good instruments are of course hard to find. We follow Hall (1988) and Ramey (1989), and use the political party of the President, the growth rate of real military spending, and the growth rate

8 The 50 types of depreciable capital, along with their estimated geometric depreciation rates, are listed in Jorgenson (1990), Table 3.6. Automobiles, for example, have a depreciation rate of 33 percent. Photocopy machines have a depreciation rate of 18 percent. Office buildings have a depreciation rate of 2.47 percent. We follow Jorgenson and assume that land and inventories do not depreciate.

9 The typical industry appears to have an average postwar profit rate of about 4 percent in our estimates. We experimented with several alternative measures of the capital cost. For example, following Hall (1990) we assumed a constant depreciation rate of 12.7 percent for all assets. We also used data on non-asset-specific measures of ITC and d, obtained from Alan Auerbach. These adjustments had no important effect on our results. This is unsurprising, since they affect the overall estimated level of profits, but have little effect on the cyclical properties of the estimated cost-of-capital series. 
of the world dollar price of oil. We also include a lag of each of these variables. Of the three variables, the price of oil has the greatest correlation with the right-hand-side variables; it is also the most questionable. Hall (1990) argues in its favor on the grounds that input prices do not shift production functions. It is not enough, however, that the production function at a point in time be unaffected. In estimating equation (6), we are explicitly focusing on how the production function changes over time; for this rate of change to be unaffected by input prices, we require that technological progress be Hicksneutral. With this assumption, the price of oil is a valid instrument.

\section{Results and Discussion}

In this section we present our major empirical results, and discuss their implications.

We reach three main conclusions. First, using gross-output data from 1953 to 1985 , we find no evidence of spillovers. Second, using our constructed value-added data, we find large apparent spillovers. Thus, with different data, we reproduce the Caballero-Lyons stylized fact that there is a strong positive correlation between aggregate inputs and industry productivity calculated from value added. Third, by augmenting data on value added and primary inputs with data on intermediate inputs, we essentially recover the gross output results with value-added data, including the finding of no positive externalities. This is an important result because it shows that many of the failures of value added come from the source we identify: specification error caused by the existence of imperfect competition.

The results are presented in Tables 1-4. In all of the tables, we constrain internal returns $\gamma$ and external spillovers $\kappa$ to be the same in all 21 industries. Allowing internal returns $\gamma$ to vary across industries barely affects our estimates of $\kappa$, the variable of primary interest here, so we do not report those results. In Table 1 we report the results using both the quality-adjusted and the non-quality-adjusted data. As we see, the two types of data give essentially identical results. Therefore, in the remaining tables we present only the results using the preferred quality-adjusted data. In no case are our 
conclusions altered by the quality adjustment.

We report all regressions both instrumented and uninstrumented. If one has complete confidence in the instruments, then the instrumented results are clearly preferable. There are two potential shortcomings to the instruments we use, however. First, even if one has complete confidence in the exogeneity of the instruments, there may be small-sample problems. Nelson and Startz (1990) show that using exogenous instruments that fit poorly may lead to substantial small sample bias (where "small" may, in fact, be large relative to the data sets used by macroeconomists.) They consider a single-equation single-variable setup, but to us their work suggests a more general concern: we are trying to disentangle the effects of two highly correlated variables (industry and aggregate inputs) from their projections onto the same set of relatively poor instruments. Second, the only instrument with any significant correlation with inputs is the price of oil. And this is the most questionable instrument, because of the possibility that technological progress is not Hicks-neutral. Hence, for comparison, we also report the uninstrumented results.

All regressions include unreported industry-specific constants and dummy variables that allow a trend break in productivity growth after 1973 . We include the post-73 dummy in response to recent work of Perron (1989) and others, who suggest that allowing for a one-time change in slope after 1973 provides a useful empirical specification for modelling trends. The post-73 dummies are generally highly significant, but none of our substantive conclusions depend on their presence.

Table 1 shows our main results. The dependent variable is the growth rate of gross output in each industry. The two columns on the left show the results when inputs are not adjusted for quality; the two columns on the right show the results when they are. The rows of the table show our estimates of the parameters in equation (10), where $\mathrm{dz}_{\mathrm{i}}$ is parameterized as $\kappa \cdot \mathrm{dx}_{\mathrm{i}}$ : internal returns $\gamma$, and output spillovers $\kappa$.

Focusing first on the estimate of returns to scale, we find essentially constant returns. Adjusting 
for quality, however, returns to scale are slightly smaller: instrumented, with quality-adjusted inputs, we estimate that $\gamma$ is about 0.96 . This is just smaller than 1 at the 95 percent level of significance: the confidence interval includes 0.99 . Since the quality of inputs has grown over our sample period, taking this fact into account shows that some of the output growth incorrectly attributed to increasing returns is actually a consequence of increasing input quality.

Turning to $\kappa$, the parameter of primary interest here, in Table 1 we find no evidence of positive output spillovers across industries. In all cases we find that $\kappa$ is essentially zero: the average $\kappa$ is -0.02 . In the one case where $\kappa$ is positive it is insignificant, and in the one case where it is significant it is negative.

In Table 2, Panel A, we show the same regressions as in Table 1, but using our constructed value-added data as the measure of output. These results differ markedly from the gross-output results. This is particularly striking because the value-added data are constructed from the same data set that we used for the gross-output regressions. Hence, we control for the myriad small differences in sources and methods that make it difficult to compare results from different data sets.

Using these value-added data we find small estimates of $\gamma$, consistently on the order of 0.6 . This accords with our prediction in Section II that the estimate of $\gamma$ from a value-added regression is biased downward. For reasons we discuss below, estimates of internal returns on the order of 0.6 are too small to be believable. Turning to $\kappa$, the spillover parameter, we find that in our value-added data $\kappa$ is large and significant--both $\mathrm{t}$-statistics exceed 4. This contrasts with the results in Table 1, where $k$ was never both positive and significant.

In Table 2, Panel B, we run the same regressions with the Caballero-Lyons data, from NIPA and BEA. $^{10}$ The results are qualitatively similar to those in Panel A, although the estimates of $\kappa$ with NIPA

10 We thank Ricardo Caballero, who generously provided the data to us. These regressions do not correspond exactly to the regressions of Caballero and Lyons (1992) because we do not include the sectoral oil price or energy use as a right-hand-side variable, and we use $\mathrm{dx}$ rather than dy as our index 
data are larger than with our value-added data. This difference may arise from the different method by which the NIPA value-added data are constructed, an issue we discuss in Appendix I.

Together, Tables 1 and 2 demonstrate empirically the pattern of results we predicted on theoretical grounds in Section II: estimates of returns to scale are biased down and estimates of external effects are biased up, relative to their true gross-output values, when the estimation is done with value-added data. We now confirm that our explanation for the failure of value added is the correct one. Equation (10) specifies the exact manner in which value added should fail. This equation predicts that the major source of the difference in results is the omission of materials growth as a right-hand-side variable. If our explanation is correct, then by estimating equation (10) we should get exactly the same $\gamma$ 's as in Table 1 and $\kappa$ 's that are about twice as large. (The reason that $\kappa$ should be larger is given in equations (12) or (10): with value added, the effect of the externality is scaled up by a factor of $1 /\left(1-\mathrm{s}_{\mathrm{M}}\right)$. In the data, $\mathrm{s}_{\mathrm{M}}$ is on the order of $0.5-0.6$ over our sample period.)

We estimated equation (10) using both our value-added data and the NIPA data. Table 3 reports our results. For our data, they conform very well to our predictions. In the case of the instrumented regression the parameter estimates are just what we expect: $\gamma$ is almost identical to its Table 1 counterpart and $\kappa$ is multiplied by a factor of about 2.5. The uninstrumented results are also very close.

Applying our corrections to the NIPA data, however, does not give exactly the results of Table 1. It is nevertheless clear that the failures we identify do apply to the NIPA data. The changes in the parameter estimates are very similar: $\gamma$ rises significantly and $\kappa$ falls significantly. In the case of the instrumented results, even with the NIPA data, $\kappa$ becomes insignificantly different from zero, while $\gamma$ increases from 0.8 to 1.1 (significantly increasing returns to scale). Thus, we attribute the (instrumented) results of Caballero and Lyons (1992) to the specification error we discussed in Section II. When we do not instrument the NIPA data, however, $k$ is reduced by a third relative to its value in Table 2, yet it

of externalities. 
remains large. Why the instrumented and uninstrumented results are so different remains a puzzle.

In Section II, we identified two separate misspecifications with value-added data. Here we ask which of these misspecifications has a greater empirical effect. In Table 4A, we correct for the first problem only: the fact that $\mathrm{dx}^{v}$ should be multiplied by $\left(1-\mathrm{c}_{\mathrm{M}}\right) /\left(1-\mathrm{s}_{\mathrm{M}}\right)$. In Table $4 \mathrm{~B}$ we correct for the second problem only: we include the omitted materials growth term as required in equation (10). Comparing the results with those of Table 3 shows that the omission of the materials term is quantitatively more important. This fits our theoretical prediction, since profit rates are relatively small, and $\left(1-c_{M}\right) /\left(1-s_{M}\right)$ is not very cyclical. This conclusion holds for both data sets.

We view our findings as methodologically significant. They show not only that gross-output data gives results quite different from results with value added; they also confirm empirically our predictions about why value added is inappropriate. But our methodological findings should not overshadow the significance of our substantive results. We find that internal returns to scale are roughly constant, but certainly not strongly decreasing as the value-added results suggest. Most interestingly, we find no evidence of positive, contemporaneous spillovers from aggregate activity.

That value-added estimates give strongly diminishing returns has not received as much attention as the finding of spillovers, but it gives yet another strong reason to be wary of these results. ${ }^{11}$ Most plant and engineering studies find returns to scale essentially constant. For example, Griliches and Ringstad (1971) find $\gamma$ to be on the order of 1.03-1.05. Baily, Hulten, and Campbell (1992) use plantlevel data and find that returns to scale are roughly constant (with more estimates slightly below 1 than

1 Hall (1990) uses value-added data, and finds increasing returns. In a companion paper, Basu and Fernald (1994), we argue that this arises from the omitted-variable bias we identified in Section II. Since Hall's regressions do not include an aggregate activity variable, in his case the specification error biases up the estimated returns to scale. 
above). ${ }^{12}$ As Griliches and Ringstad observe, essentially constant returns are needed to rationalize the observation that there is often a large dispersion of establishment sizes within a given industry. Estimates of $\gamma$ from value added, like the ones we report above, imply that firms should want to have a huge number of plants, each operating at a minuscule scale.

Fixed costs do not suffice to resolve this paradox. With fixed costs and perfect competition, each firm will operate on average at the minimum of the average cost curve, the point where returns to scale are locally constant. With Chamberlinian monopolistic competition firms operate where there are locally increasing returns, i.e., on the downward-sloping portion of the average cost curve. Some industrial-organization models of entry deterrence predict that firms should carry excess capacity (Bulow, Geanakoplos, and Klemperer, 1985): this again predicts that firms operate at a point of locally increasing returns. We are not aware of any model with fixed costs that predicts that firms will on average produce at a point where there are diminishing returns to scale (as distinguished from increasing marginal cost).

Apart from these considerations, a $\gamma$ that is significantly less than 1 is internally inconsistent with the assumed monopolistic-competition framework (or, indeed, with any form of profit maximization). Note from equation (4) that unless profit rates are huge (which in the data they are not), a $\gamma$ of 0.6 or even 0.8 implies that the markup of price over marginal cost, $\mu$, is less than 1 -- i.e. firms sell output below marginal cost. This conclusion is independent of any possible externalities and gives perhaps the strongest reason for doubting these low estimates of $\gamma$.

Our results with gross-output data, however, seem quite reasonable. In terms of economic significance we find constant returns to scale. With the profit rates we calculate, this implies a small but significant markup: prices are on the order of 5 percent above marginal cost. This calculation is,

12 They use a sample of plants from 23 four-digit industries in the Longitudinal Research Database for the last four census years $(1972,77,82,87)$. "If anything," they write, "there is some sign of decreasing returns, especially in the later years, but a vote for constant returns at the plant level looks like a pretty good bet (p. 235)." 
however, sensitive to an accurate computation of profit rates. The profit rates we compute are particularly low (sometimes negative) in the 1970s. Here it is possible that our required payments to capital are too high because we do not account for capital losses on existing plant and equipment following the oil price shocks. ${ }^{13}$ As an alternative strategy, we estimate equation (12) to get a direct estimate of the markup, $\mu$. (Assuming that both $\gamma$ and $\mu$ are constant is equivalent to assuming that the true profit rate is a constant.) We find $\mu$ to be about 1.15 , implying prices about 15 percent higher than marginal costs. Hence the implied markup and profit rates from these two procedures range between 5 and 15 percent: a strong indication of imperfect competition, but small enough to be plausible.

Turning to productive spillovers, the part of Caballero and Lyons's findings that has excited a great deal of interest in the literature, we find no evidence of positive externalities from contemporaneous activity in manufacturing to the production functions of firms within a specific industry. We have presented evidence that results to the contrary are a consequence of specification error.

What accounts for the differences between our results and those of Bartelsman, Caballero, and Lyons (1994)? They, too, use gross-output data, albeit at the level of four-digit industries, and find evidence of externalities from aggregate input use. They have detailed information on the structure of the input-output matrix for their industries, which allows them to construct different measures of the aggregate input variable that is relevant for each industry over different periods of time. In the short run, externalities appear to arise primarily from the activity of an industry's customers; in the long run, however, externalities appear to arise instead from the activity of an industry's suppliers. Bartelsman et. al. estimate a statistically-significant coefficient for the short-run externality of about 0.12 .

An earlier (1991) version of their paper indicates that most of their externalities come from other two-digit industries, not from within the same industry group. Hence, the differences between our results

\footnotetext{
${ }^{13}$ This is consistent with the observation that the stock market was depressed but investment was high following the oil price shocks. See the discussion in note 2 .
} 
and theirs are not explained simply by externalities at the four-digit level that are internalized at the twodigit level. In principle, disaggregating makes sense, given the greater amount of information (450 fourdigit manufacturing industries versus 21 two-digit industries) and given the problems posed by aggregation theory. In practice, however, the data is more reliable at a two-digit that a four-digit level. As a result, we remain skeptical of the Bartelsman et. al. results.

First, the four-digit data on intermediate inputs does not include business services. These services have become increasingly important over time, so their omission is potentially serious. That is, output depends on observed inputs and omitted business services. The use of these omitted inputs may well be correlated with aggregate inputs, and hence may show up as an external effect. Second, the weights on capital and labor are problematic in the Bartelsman et. al. data. Labor cost is based on payroll, not compensation. Hence, it omits factor costs such as FICA, health insurance, and pensions. The effect of this is to underweight labor relative to capital. Since labor input is more cyclical than capital input, measured productivity becomes more cyclical than true productivity.

Another potential explanation for the difference in results, however, is that the sample periods differ. Bartelsman et. al. estimate their regressions over the period 1959-86. Our data are available only through 1985; but for comparison, we estimated our basic gross-output regressions over the reduced period 1959-85. The uninstrumented regression continues to show no evidence of external effects. Instrumenting, however, the estimate of $\kappa$ is 0.08 with a standard error of 0.02 . This is relatively close to though still smaller than the results of Bartelsman et. al.

A finding of contemporaneous spillovers of 0.10 or smaller, whose presence is highly sensitive to the type of data, the estimation technique, and the precise sample period, is probably not very significant economically. For this reason, we conclude that internal returns to scale are about constant, and external effects from contemporaneous aggregate activity are probably not present. Nevertheless, despite our skepticism about the short-run results of Bartelsman et. al., we find their tong-run supplier- 
driven externalities interesting and potentially important. We find it easier to tell a long-run dynamic story of externalities--arising, for example, from the embodiment of ideas in goods or from learning-bywatching. This appears to us to be fertile ground for future research.

\section{Conclusion}

In this paper, we provide an explanation for the stylized fact that regressions using value-added data in two-digit manufacturing appear to imply large productive spillovers to output. We show why, in the presence of imperfect competition, the use of value-added data will likely cause one to find large apparent externalities, even if such externalities do not in fact exist.

Using theoretically-preferable gross-output data, we find no evidence of output spillovers. When we construct value-added data, however, we find large apparent spillovers. We then augment data on value added and primary inputs with data on intermediate inputs in the way our theoretical specification requires; we again find that spillovers are non-existent. This confirms our conjecture that the misspecifications of value added we identify as a matter of theory are actually responsible for the differences in results.

The specification errors we identify have an important implication: value-added data are not appropriate for estimating structural parameters, except with competition and constant returns. Hence, our critique applies equally to the work of Hall $(1986,1988,1990)$, who uses the same data as Caballero and Lyons in order to estimate markups and returns to scale. In a related paper (Basu and Fernald 1994), we argue that Hall's finding of increasing returns arises from the misspecification we identified in Section II: his estimates of returns to scale are inflated due to omitted variable bias from ignoring the effects of intermediate input growth. As we show in this paper, Hall's data suggests that returns to scale are close to constant. We do, however, find evidence of small, though significant, markups of price over marginal cost. 
Our results paint a very different picture of the economy than the one suggested by previous empirical work and incorporated into recent theoretical papers. We find essentially constant returns, no short-run spillovers, and small markups of price over marginal cost. Our results suggest that business cycle models cannot plausibly be based on increasing returns or productive externalities. 


\section{Appendix I: Alternative Measures of Real Value Added}

In Section II, we discussed the statistical properties of a Divisia index of real value added. The Bureau of Economic Analysis, in constructing the NIPA data, instead uses three alternative methods to estimate real value added: double deflation, single deflation, and extrapolation (see Waldmann, 1991). This appendix discusses how these measures relate to the Divisia method.

The Divisia method assumes that the weights on output and intermediate inputs are adjusted continuously. It is useful to rewrite equation (8) as

$$
d v=d y-\frac{s_{M}}{1-s_{M}}(d m-d y)
$$

Double Deflation: The NIPA uses double deflation for all manufacturing industries except petroleum and coal products (SIC 29). If we normalize the base-year prices of gross output and intermediate inputs to one, the double-deflated estimate of real value added, $V_{i}{ }^{D D}$, is

$$
V^{D D}=Y-M
$$

Let $n$ equal $M / Y$, the share of output going to materials in base-year prices. Differentiating equation (A-2) and rearranging, we find that the growth rate of double-deflated value added is:

$$
d v^{D D}=d y-\frac{n}{1-n}(d m-d y)
$$

The difference between the double-deflated index and the Divisia index is the weights used to subtract materials growth from output growth. The double-deflated index calculates the weights using constant base-year prices, whereas the Divisia index calculates the weights using current prices. Combining (A-1) and (A-3), we can write the growth rate of double-deflated value added as the growth rate of the Divisia index, plus an additional term:

$$
d v^{D D}=d v+\frac{n}{(1-n)\left(1-S_{M}\right)}\left(1-\frac{P_{M}}{P}\right)(d y-d m) .
$$

The second term in equation (A-4) is the double-deflation bias. As Bruno (1978) and Bruno and Sachs 
(1985) point out, this bias term disappears in two special cases: if intermediate inputs grow at the same rate as gross output, or if the price of intermediate inputs relative to the price of output always equals one.

Single deflation: Single-deflated value added (used, for example, by Bartelsman, Caballero, and Lyons (1991)) is calculated by deflating nominal value added by the gross-output deflator. That is,

$$
V^{S D}=\frac{\left(P \cdot Y-P_{M} \cdot M\right)}{P}=Y-\left(\frac{P_{M}}{P}\right) M
$$

Differentiating equation (A-5), we find that the growth rate of the single-deflated index of value added again equals the growth of the Divisia index, plus an additional term:

$$
d v^{S D}=d v+\left(\frac{s_{M}}{1-s_{M}}\right) \frac{d\left(P_{M} / P\right)}{\left(P_{M} / P\right)} .
$$

It is clear from equation (A-6) that single-deflated measures of value added are directly shifted by changes in the relative prices of intermediate inputs.

Extrapolation: For some industries, NIPA calculates real value-added by extrapolating the baseyear value added by an indicator series, such as real gross output or hours worked. In the NIPA manufacturing data we use, value added in petroleum and coal products is extrapolated based on gross output. Hence,

$$
d v^{E}=d y=d v+\frac{s_{M}}{1-s_{M}}(d m-d y)
$$

Extrapolation gives the same results as the Divisia index (and double-deflation) if intermediate inputs are used in fixed proportions to output.

In sum, we find that alternative measures of real value added suffer from the same misspecifications as the Divisia index of value added. There is then an additional misspecification in each case. 


\section{BIBLIOGRAPHY}

Arrow, K., 1974, The measurement of real value added, in: P. David and M. Reder, eds., Nations and households in economic growth: Essays in honor of Moses Abramovitz (Academic Press, New York).

Baily, M.N., C. Hulten and D. Campbell, 1992, Productivity dynamics in manufacturing plants, Brookings Papers on Economic Activity (Microeconomics), 187-267.

Bartelsman, E., R. Caballero, and R. Lyons, 1991, Short and long-run externalities, NBER Working Paper No. 3810.

Bartelsman, E., R. Caballero, and R. Lyons, 1994, Customer- and supplier-driven externalities, American Economic Review, forthcoming.

Basu, S. and J.G Fernald, 1994, Constant returns and small markups in U.S. manufacturing, Board of Governors of the Federal Reserve System, International Finance discussion paper.

Baxter, M. and R. King, 1991, Productive externalities and business cycles, Federal Reserve Bank of Minneapolis, Institute for Empirical Macroeconomics discussion paper \#53.

Braun, R. A. and C. L. Evans, 1991, Seasonal Solow residuals and Christmas: A case for labor hoarding and increasing returns, Federal Reserve Bank of Chicago WP-91-20.

Bruno, M., 1978, Duality, intermediate inputs, and value-added, in: M. Fuss and D. McFadden, eds., Production economics: A dual approach to theory and practice, Volume 2 (North-Holland, Amsterdam).

Bruno, M. and J. Sachs, 1985, The economics of worldwide stagflation (Harvard University Press, Cambridge).

Bulow, J., J. Geanakoplos and P. Klemperer, 1985, Holding idle capacity to deter entry, Economic Journal 95, 178-182.

Caballero, R. and R. Lyons, 1989, The role of externalities in U.S. manufacturing, NBER Working Paper No. 3033.

Caballero, R. and R. Lyons, 1990, Internal and external economies in European industries, European Economic Review 34, 805-830.

Caballero, R. and R. Lyons, 1992, External effects in U.S. procyclical productivity, Journal of Monetary Economics 29, 209-226.

Ciccone, A. and K. Matsuyama, 1993, Start-up costs and pecuniary externalities as barriers to economic development, NBER Working Paper No. 4363.

Diamond, P., 1982, Aggregate demand management in search equilibrium, Journal of Political Economy 90, 881-94. 
Griliches, Z. and F. Lichtenberg, 1984, Interindustry technology flows and productivity growth: A reexamination, Review of Economics and Statistics 61, 324-329.

Griliches, Z. and V. Ringstad, 1971, Economies of scale and the form of the production function (North-Holland, Amsterdam).

Grossman, G.M. and E. Helpman, 1991, Innovation and growth in the global economy (MIT Press, Cambridge).

Hall, R., 1986, Market structure and macroeconomic fluctuations, Brookings Papers in Economic Activity 2, 285-322.

Hall, R., 1988, The relation between price and marginal cost in U.S. industry, Journal of Political Economy 96, 921-947.

Hall, R., 1990, Invariance properties of Solow's productivity residual, in Diamond, Peter, ed, Growth/Productivity/Employment (MIT Press, Cambridge) 71-112.

Hall, R. and D. Jorgenson, 1967, Tax policy and investment behavior, American Economic Review 57, 391-414.

Jaffe, A.B., 1986, Technological opportunity and spillovers of R\&D: Evidence from firms' patents, profits, and market value, American Economic Review 76, 984-1001.

Jorgenson, D., 1990, Productivity and economic growth, in: E. Berndt and J. Triplett, eds., Fifty years of economic measurement (University of Chicago Press, Chicago).

Jorgenson, D., F. Gollop, and B. Fraumeni, 1987, Productivity and U.S. economic growth (Harvard University Press, Cambridge).

Kiyotaki, N., 1988, Multiple expectational equilibria under monopolistic competition, Quarterly Journal of Economics 103, 695-714.

Nelson, C. R. and R. Startz, 1990, Some further results on the exact small sample properties of the instrumental variables estimator, Econometrica, 58, 967-76.

Perron, P., 1989, The great crash, the oil price shock, and the unit root hypothesis, Econometrica 57, 1361-1401.

Ramey, V. A., 1989, Inventories as factors of production and economic fluctuations, American Economic Review 79, 338-354.

Romer, P., 1987, Growth based on increasing returns based on specialization, American Economic Review Papers and Proceedings 77, 56-62.

Sato, K., 1976, The meaning and measurement of the real value added index, Review of Economics and Statistics 58, 434-442.

Waldmann, R., 1991, Implausible results or implausible data? Journal of Political Economy 99, 1315-1328. 
Weitzman, M. L., 1982, Increasing returns and the foundations of unemployment theory, Economic Journal 92, 787-804. 
TABLE 1

GROSS-OUTPUT RESULTS

\begin{tabular}{|c|c|c|c|c|}
\hline \multirow{2}{*}{ Parameter } & \multicolumn{2}{|c|}{ Quality adjusted } & \multicolumn{2}{|c|}{ Non-quality adjusted } \\
\hline & SUR & 3SLS & SUR & 3SLS \\
\hline $\begin{array}{c}\text { Internal Returns } \\
\text { to Scale } \gamma\end{array}$ & $\begin{array}{c}1.00 \\
(0.009)\end{array}$ & $\begin{array}{c}0.96 \\
(0.014)\end{array}$ & $\begin{array}{c}1.02 \\
(0.009)\end{array}$ & $\begin{array}{c}1.00 \\
(0.013)\end{array}$ \\
\hline Externalities $\kappa$ & $\begin{array}{c}-0.02 \\
(0.011)\end{array}$ & $\begin{array}{c}0.01 \\
(0.016)\end{array}$ & $\begin{array}{l}-0.035 \\
(0.011)\end{array}$ & $\begin{array}{l}-0.025 \\
(0.015)\end{array}$ \\
\hline
\end{tabular}

Standard errors in parentheses. Sample is two-digit manufacturing industries from 1953-1985.

TABLE 2

VALUE-ADDED RESULTS

\begin{tabular}{||c||c|c|}
\hline \multicolumn{1}{|c||}{ Parameter } & \multicolumn{2}{|c|}{ Panel A: Divisia Value Added } \\
\cline { 2 - 3 } & SUR & 3SLS \\
\hline $\begin{array}{c}\text { Internal } \\
\text { Returns to } \\
\text { Scale } \gamma\end{array}$ & $\begin{array}{c}0.61 \\
(0.029)\end{array}$ & $\begin{array}{c}0.62 \\
(0.050)\end{array}$ \\
\hline $\begin{array}{c}\text { Externalities } \\
\kappa\end{array}$ & $\begin{array}{c}0.16 \\
(0.037)\end{array}$ & $\begin{array}{c}0.51 \\
(0.10)\end{array}$ \\
\hline
\end{tabular}

\begin{tabular}{|c|c|}
\hline \hline \multicolumn{2}{|c|}{ Panel B: NIPA Value Added } \\
\hline SUR & 3SLS \\
\hline $\begin{array}{c}0.63 \\
(0.025)\end{array}$ & $\begin{array}{c}0.85 \\
(0.042)\end{array}$ \\
\hline 0.55 & $\begin{array}{c}0.63 \\
(0.077)\end{array}$ \\
\hline
\end{tabular}

Standard errors in parentheses. Sample is two-digit manufacturing industries from 1953-1985. 
TABLE 3

CORRECTED VALUE-ADDED RESULTS

\begin{tabular}{||c||c|c|}
\hline \multicolumn{1}{|c|}{ Parameter } & \multicolumn{2}{c|}{ Panel A: Divisia Value Added } \\
\cline { 2 - 3 } & SUR & 3SLS \\
\hline $\begin{array}{c}\text { Internal } \\
\text { Returns to } \\
\text { Scale } \gamma\end{array}$ & $\begin{array}{c}0.98 \\
(0.010)\end{array}$ & $\begin{array}{c}0.96 \\
(0.014)\end{array}$ \\
\hline $\begin{array}{c}\text { Externalities } \\
\kappa\end{array}$ & $\begin{array}{c}-0.08 \\
(0.030)\end{array}$ & $\begin{array}{c}0.023 \\
(0.042)\end{array}$ \\
\hline
\end{tabular}

\begin{tabular}{|c|c|}
\hline \hline \multicolumn{2}{|c|}{ Panel B: NIPA Value Added } \\
\hline SUR & 3SLS \\
\hline 0.97 & 1.09 \\
$(0.01)$ & $(0.012)$ \\
& \\
\hline 0.35 & 0.04 \\
$(0.034)$ & $(0.061)$ \\
\hline
\end{tabular}

Standard errors in parentheses. Sample is two-digit manufacturing industries from 1953-1985. 
TABLE 4A

VALUE-ADDED RESULTS, WITH $\left(1-c_{M}\right) /\left(1-s_{M}\right)$ CORRECTION

\begin{tabular}{||c||c|c|}
\hline \multirow{2}{*}{ Parameter } & \multicolumn{2}{|c|}{ Panel A: Divisia Value Added } \\
\cline { 2 - 3 } & SUR & 3SLS \\
\hline $\begin{array}{c}\text { Internal } \\
\text { Returns to } \\
\text { Scale } \gamma\end{array}$ & $\begin{array}{c}0.66 \\
(0.030)\end{array}$ & $\begin{array}{c}0.69 \\
(0.047)\end{array}$ \\
\hline $\begin{array}{c}\text { Externalities } \\
\kappa\end{array}$ & $\begin{array}{c}0.10 \\
(0.031)\end{array}$ & $\begin{array}{c}0.17 \\
(0.054)\end{array}$ \\
\hline
\end{tabular}

\begin{tabular}{|c|c||}
\hline \multicolumn{2}{|c|}{ Panel B: NIPA Value Added } \\
\hline SUR & 3SLS \\
\hline 0.68 & $\begin{array}{c}0.96 \\
(0.045) \\
(0.026)\end{array}$ \\
& \\
\hline 0.61 & $\begin{array}{c}0.39 \\
(0.058)\end{array}$ \\
\hline
\end{tabular}

Standard errors in parentheses. Sample is two-digit manufacturing industries from 1953-1985.

TABLE 4B

VALUE-ADDED RESULTS, WITH CORRECTION FOR OMITTED dm TERM

\begin{tabular}{||c||c|c|}
\hline \multicolumn{1}{|c|}{ Parameter } & \multicolumn{2}{|c|}{ Panel A: Divisia Value Added } \\
\cline { 2 - 3 } & SUR & 3SLS \\
\hline $\begin{array}{c}\text { Internal } \\
\text { Returns to } \\
\text { Scale } \gamma\end{array}$ & $\begin{array}{c}0.97 \\
(0.010)\end{array}$ & $\begin{array}{c}0.94 \\
(0.016)\end{array}$ \\
\hline $\begin{array}{c}\text { Externalities } \\
\kappa\end{array}$ & $\begin{array}{c}-0.07 \\
(0.029)\end{array}$ & $\begin{array}{c}0.034 \\
(0.052)\end{array}$ \\
\hline
\end{tabular}

\begin{tabular}{|c|c|}
\hline \multicolumn{2}{|c|}{ Panel B: NIPA Value Added } \\
\hline SUR & 3SLS \\
\hline 0.98 & $\begin{array}{c}1.04 \\
(0.012) \\
(0.006)\end{array}$ \\
& $\begin{array}{c}0.18 \\
0.32\end{array}$ \\
$(0.026)$ & $(0.069)$ \\
\hline
\end{tabular}

Standard errors in parentheses. Sample is two-digit manufacturing industries from 1953-1985. 